Original Research Paper

\title{
Physiological and Biochemical Evaluation of Fe-Efficiency in Fe-Deficient Maize Genotypes
}

\author{
${ }^{1}$ Entesar M. Essa, ${ }^{1}$ Sahar M. Zaghloul, ${ }^{3}$ Z.A. Salama, \\ ${ }^{2}$ F.A. Rakha, ${ }^{2}$ Y. Mabrouk, ${ }^{1}$ A.A. El-Bendary and ${ }^{4}$ Mohamed M. El-Fouly \\ ${ }^{I}$ Department of Plant Nutrition, National Research Centre, Cairo, Egypt \\ ${ }^{2}$ Department of Genetics, Faculty of Agriculture, Alexandria University, Egypt \\ ${ }^{3}$ Department of Plant Biochemistry, National Research Centre, Cairo, Egypt \\ ${ }^{4}$ Department of Fertilization Technology, National Research Centre, Cairo, Egypt
}

Article history

Received: $12-3-2015$

Revised: $28-3-2015$

Accepted: 06-4-2015

Corresponding Author: Mohamed M. El-Fouly Department of Fertilization

Technology, National Research Centre, Cairo, Egypt

Email: mohelfouly@link.net

\begin{abstract}
Iron $(\mathrm{Fe})$ deficiency is prevalent particularly in calcareous soils of arid and semiarid regions. The present study aimed to investigate the response of eight local maize genotypes to Fe deficiency. In addition, a Feefficient (WF9) and a Fe-inefficient (ys1) indicator genotypes were used in this study. All genotypes were grown in growth chamber for 21 days in two levels of Fe, sufficient $[+\mathrm{Fe}$ (FNS) $=20 \mu \mathrm{M}$ Fe EDTA] and deficient [-Fe $($ FNS $)=2 \mu \mathrm{M}$ Fe EDTA] Fe supply. Shoots dry weight, Fe concentration and uptake in shoots, active iron concentration, peroxidase activity and cholorophyll content were determined and their validities as screening parameters were discussed. Generally, genotype (WF9) as the Fe efficient indicator and genotype (34) were the less affected by Fe-deficiency. Genotype (ys1) as the Fe inefficient indicator and genotype (62) were highly affected when grown in the nutrient solution with the deficient $\mathrm{Fe}$ supply. The present study emphasize that shoot dry weight, $\mathrm{Fe}$ uptake, active Fe content, chlorophyll content and peroxidase activity could be used for evaluating the present maize genotypes for Fe efficiency.
\end{abstract}

\section{Keywords: Maize Genotypes, Fe Efficiency}

\section{Introduction}

Fe deficiency can reduce maize grain yield by as much as $20 \%$ (Godsey et al., 2003). Correcting Fe deficiency through soil amendments and foliar sprays of $\mathrm{Fe}$ has been partially successful considering the fact that low availability rather than low total amount usually limits Fe uptake by plant roots. Furthermore, Mengel (1994) suggested that $\mathrm{Fe}$ availability in calcareous soils is not the critical process leading to chlorosis but rather the Fe uptake from the root appoplast into the cytosol of root cells turned to be the limiting factor. On the other hand, many food systems in developing countries cannot provide sufficient micronutrient content to meet the demands of their citizens, especially low-income families, because of low content of micronutrients in food is mostly related with low uptake.

There are several solutions such as soil and foliar fertilization, crop systems, application of organic amendments to correct micronutrients deficiency and to increase their density in edible parts of plants. Considering ecological concerns, cultivation and breeding of micronutrient-efficient genotypes in combination with proper agronomic management practices appear as the most sustainable and costeffective solution for alleviating food-chain micronutrient deficiency. Micronutrient-efficient genotypes could provide a number of benefits such as reductions in the use of fertilizers, improvements in seedling vigor and resistance to biotic and abiotic stresses. Using bioavailable micronutrient-dense staple crop cultivars can also be used to improve the micronutrient nutritional status of human (Khoshgoftarmanesh et al., 2010).

Genotypic variation for Fe efficiency and resistance to $\mathrm{Fe}$ Deficiency Chlorosis (IDC) has been widely reported in maize and many plant species. Thus, potential exists for improving maize plants for $\mathrm{Fe}$ efficiency by breeding. The first step in a breeding program is screening and selection of the genetic material. Selection for Fe efficiency and IDC-resistance is made difficult by soil heterogeneity and highly variable environmental conditions that affect expression of the trait in the field. A simple, low cost and reliable screening procedure is required for breeding genotypes for Fe efficiency and IDC-resistance. The existence of 
indicator genotypes for Fe efficiency are of significant importance for screening purposes, as they provide a scale of measurement (the hypothetical distance between the efficient and inefficient genotypes) and help to predict the relative position of a certain genotype on the scale (El-Bendary and Roemheld, 1998).

In this study, changes in $\mathrm{Fe}$ concentration, Fe uptake, active Fe content, chlorophyll content and peroxidase activity were examined in order to better understand the response triggered by iron starvation.

\section{Materials and Methods}

\section{Plant Materials}

The seed samples of the Fe- efficient $(+/+)$ maize cv. WF9 and the Fe-inefficient (ys1/ys1) mutant were kindly provided by Prof. Marty Sachs, Maize Genetics Cooperation Stock Center, University of Illinois, USA. In addition, eight inbred lines used in maize breeding programs in Egypt, namely: 34, 628, 602, 62, 104, 653, 639 and 7 were kindly provided by Prof. Mohamad Abd El Satar, Faculty of Agriculture, Alexandria University, Egypt.

\section{Plant Culture}

Seeds were surfaced-sterilized in $10 \%$ Clorox for 10 min, rinsed thoroughly in tap water and soaked for 3 to 4h (Mansfield and Key, 1987). The germination was carried out in sand culture at $28^{\circ} \mathrm{C}$ in dark. After fivedays germination seedlings of each genotype were transferred to $1 \mathrm{~L}$ pots (5 seedlings/pot), containing a continuously aerated nutrient solution (Hoagland and Arnon, 1950) of the following composition in (mM): $\mathrm{Ca}\left(\mathrm{NO}_{3}\right)_{2} \cdot 4 \mathrm{H}_{2} \mathrm{O}, \quad$ (5); $\mathrm{KNO}_{3}, \quad$ (5); $\mathrm{KH}_{2} \mathrm{PO}_{4}, \quad$ (1); $\mathrm{MgSO}_{4} \cdot 7 \mathrm{H}_{2} \mathrm{O}$, (2); micronutrients (in $\mu \mathrm{M}$ ): $\mathrm{H}_{3} \mathrm{BO}_{3}$, (10); $\mathrm{MnCl}_{2},(0.5) ; \mathrm{ZnSO}_{4},(0.5) ; \mathrm{CuSO}_{4},(0.2) ; \mathrm{Na}_{2} \mathrm{MoO}_{4}$, (0.1). Fe was supplied as Fe(III)-EDTA $(20 \mu \mathrm{M})$. After four days of growing in the nutrient solution with the sufficient level of Fe $(20 \mu \mathrm{M})$, treatment was started by growing genotypes in two levels of Fe: Deficient-Fe supply (-Fe $=2 \mu \mathrm{M}$ Fe EDTA) or sufficient-Fe supply $(+\mathrm{Fe}=20 \mu \mathrm{M}$ Fe EDTA). All plants were grown in a growth chamber for 21 days $60 \%$ relative humidity, light intensity of $120 \mu \mathrm{mol} \mathrm{m} \mathrm{sec}^{-1}$ at plant height and $\left(25 / 20^{\circ} \mathrm{C}\right)$ day night regime. The nutrient solution was changed at two days interval.

\section{Determinations}

Shoot samples of 21 days old seedlings were immerged several times in distilled water then oven dried at $105^{\circ} \mathrm{C}$, weighed, ground and digested with acids mixture. Fe concentration in shoots was determined using Perkin-Elmer atomic absorption spectrophotometer (Chapman and Pratt, 1978). Active iron $\left(\mathrm{Fe}^{+2}\right)$ concentration in fresh leaves was determined according to Takkar and Kaur (1984). Chlorophyll (chlorophyll a and b) was extracted from fresh leaf tissue with $80 \%$ acetone, then the absorbency was determined at 645 and $663 \mathrm{~nm}$ with LKB spectrophotometer and chlorophyll concentration (mg/g f.wt.) were calculated according to the equations of Lichtenthaler (1987). Peroxidase enzyme activity was assayed spectrophotochemically according to Amako et al. (1994).

\section{Statistical Analysis}

The experiment was conducted in a completely randomized design with three replicates. Data obtained from samples with the same experimental conditions were statistically analyzed using MSTAT-C Package program (Russell, 1986). When variance generated significant F-value $(p<0.05)$, the mean values of the maize genotypes between and within the two levels of $\mathrm{Fe}$ were compared by the Least Significant Difference test (LSD) at the 0.05 level of probability as illustrated by (Little and Hills, 1978).

\section{Results and Discussion}

\section{Shoots Dry Weight}

Shoots (stems and leaves) dry weight of the present maize genotypes was used as a preliminary evaluation for the response to $\mathrm{Fe}$ deficiency (Table 1). The results revealed that shoots dry weight of the ten maize genotypes responded differently to iron treatment. Shoot dry weight of the Fe-efficient standard genotype (WF9), in addition to the genotypes (34 and 628) were less affected by Fe-deficiency in the culture media. In contrast, shoots dry weight of the Fe-inefficient yellow stripe (ys1) standard genotype in addition to the genotypes $(104,602,62,653,639$ and 7) were negatively affected when grown in the Fe-deficient nutrient culture. The percentage relative reduction values of shoot dry weight as an indicator of Fe-efficiency of the present maize genotypes revealed, as expected, that the standard Fe-efficient maize genotype (WF9) was the less affected by the absence of Fe in the nutrient culture. On the other hand, the standard Fe-inefficient yellow Stripe (ys1) maize genotype was the most highly affected among the present ten maize genotypes .Concerning the response of shoots dry weight to $\mathrm{Fe}$ treatment; it seems that genotypes $(628,639,34$ and 602) had similar response to Fe-deficiency as the Feefficient standard genotype (WF9). On the other hand, it could be observed that the genotype (62) had similar response to Fe-deficiency as the standard Fe-inefficient (ys1) genotype. Between these categories, the genotypes ( 7 and 653) could be placed as intermediate concerning the response to Fe-deficiency.

El-Bendary and Salama (1998) reported that the increase of Fe-concentration in Hoagland solution resulted in a significant increase in shoot dry weights in varieties of faba bean. Similar results were reported by Krishnasamy et al. (2005) on sorghum genotypes and Salama et al. (2009) on maize. 
Table 1. Shoots (stems + leaves) dry weight (g/plant) and calculated relative reduction (RD\%) of shoots dry weight of the ten maize genotypes grown in nutrient solution for three weeks in sufficient $[+\mathrm{Fe}(\mathrm{FNS})=20$ $\mu \mathrm{M}$ Fe EDTA] and deficient $[-\mathrm{Fe}$ (FNS) $=2 \mu \mathrm{M}$ Fe EDTA] Fe supply

\begin{tabular}{|c|c|c|c|}
\hline \multirow[b]{2}{*}{ Genotypes } & \multicolumn{3}{|c|}{ Shoot dry weight (g/plant) } \\
\hline & $+\mathrm{Fe}(\mathrm{FNS})^{*}$ & $-\mathrm{Fe}(\mathrm{FNS})^{*}$ & $\mathrm{RD} \% * *$ \\
\hline$\overline{34}$ & 0.07 & 0.06 & -14 \\
\hline 628 & 0.08 & 0.07 & -13 \\
\hline 602 & 0.11 & 0.09 & -18 \\
\hline 62 & 0.07 & 0.04 & -43 \\
\hline 104 & 0.09 & 0.06 & -33 \\
\hline 653 & 0.09 & 0.06 & -33 \\
\hline 639 & 0.15 & 0.13 & -13 \\
\hline 7 & 0.07 & 0.05 & -29 \\
\hline WF9 & 0.11 & 0.10 & -6 \\
\hline ys1 & 0.07 & 0.04 & -43 \\
\hline L.S.D $(0.05) 1$ & 0.02 & 0.02 & \\
\hline L.S.D $(0.05) 2$ & 0.02 & & \\
\hline
\end{tabular}

1. L.S.D between genotype means at the same level of Fe.

2. L.S.D for the same genotype at different levels of Fe.

*FNS: Full Nutrient Solution

$* *$ Relative Reduction $(\mathrm{RD}) \%=(-100) \frac{(+F e)-(-F e)}{(+F e)}$

Table 2. Fe-concentration ( $\mu \mathrm{g} / \mathrm{g} \mathrm{DW})$ and calculated relative reduction (RD\%) in shoots (stems + leaves) of the ten maize genotypes grown in nutrient solution for three weeks in sufficient $[+\mathrm{Fe}(\mathrm{FNS})=20 \mu \mathrm{M}$ Fe EDTA] and deficient $[-\mathrm{Fe}$ (FNS) $=2 \mu \mathrm{M}$ Fe EDTA] Fe supply

\begin{tabular}{|c|c|c|c|}
\hline \multirow[b]{2}{*}{ Genotypes } & \multicolumn{3}{|c|}{ Iron concentration $(\mu \mathrm{g} / \mathrm{g} D W)$} \\
\hline & $+\mathrm{Fe}(\mathrm{FNS}) *$ & $-\mathrm{Fe}(\mathrm{FNS}) *$ & $\mathrm{RD} \%$ \\
\hline 34 & 180 & 172 & -4.4 \\
\hline 628 & 146 & 127 & -13.0 \\
\hline 602 & 163 & 154 & -5.5 \\
\hline 62 & 93 & 54 & -42.0 \\
\hline 104 & 101 & 97 & -4.0 \\
\hline 653 & 160 & 142 & -11.3 \\
\hline 639 & 99 & 43 & -56.6 \\
\hline 7 & 156 & 149 & -4.5 \\
\hline WF9 & 162 & 151 & -6.8 \\
\hline $\mathrm{ys}_{1}$ & 68 & 36 & -47.0 \\
\hline L.S.D $(0.05) 1$ & 17 & 17 & \\
\hline L.S.D $(0.05) 2$ & 16 & & \\
\hline
\end{tabular}

1. L.S.D between genotypes means at the same level of $\mathrm{Fe}$

2. L.S.D for the same genotypes at different levels of $\mathrm{Fe}$ *FNS: Full Nutrient Solution

$* *$ Relative Reduction $(R D) \%=(-100) \frac{(+F e)-(-F e)}{(+F e)}$

Krishnasamy et al. (2005) screened sorghum genotypes and they stated that Fe-efficient genotype should not only be able to absorb more Fe from deficient soils but should also produce more dry matter and grain yield. Celik and Katkat (2008) found the root and shoot dry weight values of maize varieties grown in iron free nutrient solution were severely affected and gave the lowest dry weight values. Similar results were observed by Jelali et al. (2012).

\section{Fe-Concentration}

Significant differences were observed among the present maize genotypes for $\mathrm{Fe}$ concentration in shoots either at the same level of $\mathrm{Fe}$ or at the different levels of Fe-treatment (Table 2). At Fe supply $(+\mathrm{Fe})$, the highest Fe-concentrations in shoots were detected in genotypes (34, 602 and WF9), while the lowest Fe-concentration in shoots were detected in ysl genotype. At deficient Fe supply (-Fe), the highest Fe-concentrations in shoots were observed in genotypes $(34,602$, WF9), while the lowest Fe-concentrations in shoots were observed in genotypes (ys1 and 639). On the other hand, different response to deficient Fe supply was observed in Fe-concentrations when compared with the same genotypes in Fe treatment. Fe-concentrations in shoots of (ys1, 639, 653, 62 and 628) genotypes grown in deficient Fe-supply were negatively affected when compared with the same genotypes grown in sufficient Fe-supply. No significant differences were observed for Fe-concentration in shoots of (WF9, 7, 34, 602 and 104) genotypes for both treatments.

Although these data may indicate that Feconcentration in shoots dry weight of the present maize genotypes may be an indicator for Fe-efficiency, many previous results were in disagreement with this conclusion. Confirmed results from maize and other cereal species indicated that the concentration of $\mathrm{Fe}$, among other micronutrients, is not a reliable parameter for distinguishing sensitivity to Fe-deficiency among plant genotypes. Wallace et al. (1976a) and Katyal and Sharma (1980) concluded that $\mathrm{Fe}$ concentration techniques for diagnosing $\mathrm{Fe}$ deficiency in plant are generally considered unsatisfactory, because total Fe concentration in plant does not correlate with plant growth response to Fe. El-Bendary and Roemheld (1998) reported that $\mathrm{Fe}$-concentration in shoot was not a suitable parameter for evaluating Fe-efficiency and it was not related to Fe-efficiency. El-Bendary et al. (1999) found that total $\mathrm{Fe}$ concentration in leaves is not a suitable indicator for assessing chlorosis expression in plants. Pestana et al. (2003) found that in the case of the Fedeficiency, sometimes, the total iron content might not reflect the iron nutritional status of the plant. It has been established that when plants are grown under $\mathrm{Fe}-$ deficiency in field conditions, the total leaf $\mathrm{Fe}$ concentration is generally the same or even higher than in Fe-sufficient plants. Nenova and Stoyanov (1999) found that Fe-deficiency resulted in rapid and strong decrease of root $\mathrm{Fe}$ concentration. Despite the low total $\mathrm{Fe}$ in the leaves of chlorotic plants, the $\mathrm{Fe}$ concentration in leaves did not reflect the Fe supply to plants. 


\section{Iron Uptake}

Shoots content of the present genotypes showed that the Fe efficient standard genotype (WF9) and genotype (34) were less affected by Fe deficiency in the nutrient solution (Table 3). In contrast, shoots uptake of the Fe inefficient yellow stripe (ys1) standard genotype, in addition to genotypes (62 and 639) were highly affected when grown in the Fe deficient nutrient culture. These results are confirmed by the Fe efficiency scale expressed as the percentage relative reduction values of shoots uptake of the present genotypes. Moreover, a clear correlation was observed between Fe-deficiency symptoms and Fe-uptake pattern of the present genotypes. WF9, 34, 602 and 628 with slight deficiency symptoms contained more iron in shoots than other genotypes with severe deficiency symptoms. In addition, the present results revealed that among the Fe deficient maize genotypes, ys 1 and 62 exhibited the highest deficiency symptoms correlated with lowest iron content in shoots.

The different uptake pattern of iron for the present genotypes is in agreement with the findings of (Clark and Brown, 1974; EL-Bendary et al., 1999) and others; they found that maize genotypes grown in calcareous soil showed wide differences in Fe uptake and utilization. Moreover, the different uptake pattern of iron of the present maize genotypes is in agreement with the fact that some plant species and cultivars of the same species have evolved a mechanism for more efficient uptake under deficiency of some elements (El-Bendary et al., 1998; Cakmak et al., 1999). El-Bendary and Roemheld (1998) suggested that shoot uptake is suitable for selecting the most inefficient lines of maize.

\section{Active Iron Concentration}

Data presented in Table 4 showed that active iron content in the leaves of (34 and WF9) genotypes was relatively higher under both Fe treatments. When plants grown with adequate Fe supply in the growth media, the active iron content in leaves was (41.3 and $36.3 \mu \mathrm{g} / \mathrm{g} \mathrm{F}$.W) respectively, while under $\mathrm{Fe}$ deficiency the active iron content reached (30.11 and $27.60 \mu \mathrm{g} / \mathrm{g} \mathrm{F.W})$, at 21 days old. For ys 1, 62 and 639 genotypes, the active iron content in the Fe deficient leaves of ys1, 62 and 639 was (17.4 $\mu \mathrm{g} / \mathrm{g} \quad$ F.W, $16.1 \mu \mathrm{g} / \mathrm{g} \quad$ F.W and $13.5 \mu \mathrm{g} / \mathrm{g} \quad$ F.W) respectively. Under Fe deficiency treatment the active iron decreased in ys1, 62 and 639 genotypes by 47.4, 38.6 and $37.6 \%$, respectively. For 7, 653, 602, 34, 628, WF9 and 104 genotypes, the active iron content in the leaves was decreased by $(29.6,28.9,27.9,27.1,26.3,24$ and 22\%).

These results are in a good agreement with the results of Mehrotra and Gupta (1990), they concluded that the high level of active iron detected in resistant chickpea cultivar might be the source of the ability to tolerate iron deficiency. Similar results were obtained by Ohwaki and Sugahara (1993).
Table 3. Iron uptake ( $\mu \mathrm{g} / \mathrm{plant})$ in shoots (stems + leaves) and calculated relative uptake reduction (RD \%) of the ten maize genotypes grown in nutrient solution for three weeks in sufficient $[+\mathrm{Fe}(\mathrm{FNS})=20 \mu \mathrm{M}$ Fe EDTA] and deficient $[-\mathrm{Fe}$ (FNS) $=2 \mu \mathrm{M}$ Fe EDTA] Fe supply

\begin{tabular}{lccc}
\hline & Iron uptake $(\mu \mathrm{g} /$ plant $)$ & \\
Genotypes & $+\mathrm{Fe}(\mathrm{FNS}){ }^{*}$ & -Fe(FNS)* & RD\%** \\
\hline 34 & 12.6 & 10.3 & -18 \\
628 & 11.7 & 8.9 & -24 \\
602 & 18.0 & 13.8 & -23 \\
62 & 6.5 & 2.2 & -66 \\
104 & 9.1 & 5.8 & -36 \\
653 & 14.4 & 8.5 & -41 \\
639 & 14.8 & 5.6 & -62 \\
7 & 10.9 & 7.4 & -32 \\
WF9 & 17.8 & 15.0 & -16 \\
ys 1 & 4.7 & 1.4 & -70 \\
L.S.D $(0.05) 1$ & 2.7 & 2.7 & \\
L.S.D $(0.05) 2$ & 2.9 & & \\
\hline 1. L.S.D between & & &
\end{tabular}

1. L.S.D between genotype means at the same level of Fe 2. L.S.D for the same genotype at different levels of Fe * FNS: Full Nutrient Solution

$* *$ Relative Reduction $(\mathrm{RD}) \%=(-100) \frac{(+F e)-(-F e)}{(+F e)}$

Table 4. Active iron $\left(\mathrm{Fe}^{2+}\right)$ concentration $(\mu \mathrm{g} / \mathrm{g}$ F.W) in seedling leaves of the ten maize genotypes grown in nutrient solution for three weeks in sufficient $[+\mathrm{Fe}$ $(\mathrm{FNS})=20 \mu \mathrm{M}$ Fe EDTA] and deficient $[-\mathrm{Fe}(\mathrm{FNS})=$ $2 \mu \mathrm{M}$ Fe EDTA] Fe supply

\begin{tabular}{|c|c|c|c|}
\hline \multirow[b]{2}{*}{ Genotypes } & \multicolumn{3}{|c|}{ Active iron $\left(\mathrm{Fe}^{2+}\right) \mu \mathrm{g} / \mathrm{g} \mathrm{F} . \mathrm{W}$} \\
\hline & $+\mathrm{Fe}(\mathrm{FNS})^{*}$ & $-\mathrm{Fe}(\mathrm{FNS})^{*}$ & $\mathrm{RD} \%$ \\
\hline 34 & 41.3 & 30.1 & -27.1 \\
\hline 628 & 28.9 & 21.3 & -26.3 \\
\hline 602 & 32.3 & 23.3 & -27.9 \\
\hline 62 & 25.8 & 16.1 & -37.6 \\
\hline 104 & 28.8 & 22.2 & -22.9 \\
\hline 653 & 30.4 & 21.6 & -28.9 \\
\hline 639 & 22.0 & 13.5 & -38.6 \\
\hline 7 & 30.7 & 21.6 & -29.6 \\
\hline WF9 & 36.3 & 27.6 & -24.0 \\
\hline ys1 & 33.1 & 17.4 & -47.4 \\
\hline L.S.D (0.05)1 & 3.9 & 3.9 & \\
\hline L.S.D (0.05)2 & 3.9 & & \\
\hline
\end{tabular}

1. L.S.D between genotype means at the same level of Fe

2. L.S.D for the same genotype at different levels of Fe *FNS: Full Nutrient Solution

$* *$ Relative Reduction $(\mathrm{RD}) \%=(-100) \frac{(+F e)-(-F e)}{(+F e)}$

They reported that the genotypic differences of sensitive and resistant cultivars of chickpea to Fe-deficiency were attributed to the active iron in the leaves when grown under Fe-stress. Krishnasamy et al. (2005) indicated that the active $\mathrm{Fe}$ content of sorghum leaf blades was decreased with increasing level of chlorosis. Moreover, Ramirez et al. (2002) stated that active iron content may 
be used as a reliable tool for diagnosis of Fe efficiency for rice. Mohamed et al. (2003) concluded that total Fe cannot be used as a criteria to differentiate between the Fe-deficient and non-deficient plants.

\section{Chlorophyll Content}

The mean values of total chlorophyll content of the ten maize genotypes in the presence and absence of iron supply are shown in Table 5. After 21 days, the data showed that the total chlorophyll content differed in all genotypes for both treatments. Under Fe deficiency treatment the total chlorophyll decreased in ys1, 62 and 639 genotypes by $72.1,65.4$ and $64.5 \%$, respectively. The decrease was markedly observed in ys 1 genotype, more than $(72 \%)$ reduction compared with WF9 (42.9\% reduction).

Chlorosis of young leaves is often the first visual sign of iron deficiency. It is associated not only with loss of chlorophyll, as several steps of its biosynthesis depend on $\mathrm{Fe}$, but also with changes in the expression and assembly of other components of the photosynthetic apparatus (Terry and Abadsa, 1986). Early chlorosis caused decreased photosynthetic rate, less photosynthates production, nitrogen fixation and consequently yield losses (Singh and Sahu, 1993). Iron deficient plants showed visible symptoms on their youngest leaves, which became yellow (chlorotic) due to a decrease in chlorophyll content and had lower net photosynthetic rate (Price, 1968; Terry, 1980; Misra and Srivastava, 1994; Abadia et al., 2000). Gogorcena et al. (2001) found that iron deficiency caused moderate decreases (about 8\%) in the dark-adapted efficiency of PSII. Zhang et al. (2012) found that Fe-deficiency induced chlorosis of plants growing on calcareous soil and Fedeficiency slightly reduced the chlorophyll ratio. Earlier, it was suggested that the determination of leaf chlorophyll content can be a diagnostic tool to quantify $\mathrm{Fe}$ chlorosis (Abadia, 1992). On the other hand, El-Baz et al. (1998) found that chl. $\mathrm{b}$ showed no response to different $\mathrm{Fe}$ supply in snap and faba beans.

\section{Peroxidase Activity (POD)}

Data presented in Table 6 showed the changes in peroxidase activity in leaves of the ten maize genotypes grown in nutrient solution for three weeks in sufficient and deficient Fe supply. The results revealed that the activity of peroxidase in leaves of the present genotypes was depressed markedly in Fe deficient treatment when compared with sufficient Fe treatment. Supplying plants with sufficient iron +Fe (FNS) induced significant increase in POD activity for all maize genotypes as compared with deficient iron-Fe(FNS) treatment.
Table 5. Total chlorophyll (mg/g F.W) content and calculated relative Reduction (RD\%) of the ten maize genotypes grown in nutrient solution for three weeks sufficient $[+\mathrm{Fe}(\mathrm{FNS})=20 \mu \mathrm{M}$ Fe EDTA $]$ and deficient $[-\mathrm{Fe}$ $(\mathrm{FNS})=2 \mu \mathrm{M}$ Fe EDTA] Fe supply

\begin{tabular}{llll}
\hline & Total Chlorophyll $(\mathrm{mg} / \mathrm{g} \mathrm{F} . \mathrm{W})$ & \\
Genotypes & $+\mathrm{Fe}(\mathrm{FNS})^{*}$ & - Fe(FNS)* & RD\%** \\
\hline 34 & 1.6 & 0.87 & -44.6 \\
628 & 1.4 & 0.68 & -51.1 \\
602 & 2.2 & 1.23 & -44.8 \\
62 & 0.8 & 0.29 & -65.4 \\
104 & 1.7 & 0.76 & -55.2 \\
653 & 1.2 & 0.54 & -54.8 \\
639 & 0.7 & 0.26 & -64.5 \\
7 & 1.5 & 0.74 & -49.2 \\
WF9 & 1.7 & 0.99 & -42.9 \\
ys & 1.4 & 0.39 & -72.1 \\
L.S.D (0.05)1 & 0.1 & 0.10 & \\
L.S.D (0.05)2 & 0.2 & & \\
\hline 1. L.S.D between & genotype means &
\end{tabular}

1. L.S.D between genotype means at the same level of $\mathrm{Fe}$ 2. L.S.D for the same genotype at different levels of Fe *FNS: Full Nutrient Solution

**Relative Reduction $(R D) \%=(-100) \frac{(+F e)-(-F e)}{(+F e)}$

Table 6. Peroxidase (POD) activity (U/g F.W/min) in the leaves of the ten maize genotypes grown in nutrient solution for three weeks in sufficient $[+\mathrm{Fe}(\mathrm{FNS})=20$ $\mu \mathrm{M} \mathrm{Fe}$ EDTA] and deficient $[-\mathrm{Fe}$ (FNS) $=2 \mu \mathrm{M} \mathrm{Fe}$ EDTA] Fe supply

\begin{tabular}{lccr}
\hline & POD activity (U/g F.W/min) & \\
& - & & \\
Genotypes & + Fe(FNS)* & - Fe(FNS)* & RD\%** \\
\hline 34 & 12.8 & 10.3 & -19.5 \\
628 & 12.6 & 9.0 & -28.6 \\
602 & 15.6 & 10.4 & -33.3 \\
62 & 10.6 & 5.3 & -50.0 \\
104 & 14.5 & 10.9 & -24.8 \\
653 & 11.4 & 8.4 & -26.3 \\
639 & 5.7 & 3.3 & -42.1 \\
7 & 12.3 & 7.7 & -37.4 \\
WF9 & 15.5 & 14.2 & -8.4 \\
ys & 9.2 & 4.3 & -53.3 \\
L.S.D $(0.05) 1$ & 1.9 & 1.9 & \\
L.S.D $(0.05) 2$ & 1.9 & & \\
\hline
\end{tabular}

1. L.S.D between genotype means at the same level of $\mathrm{Fe}$

2. L.S.D for the same genotype at different levels of $\mathrm{Fe}$ *FNS: Full Nutrient Solution

**Relative Reduction $(\mathrm{RD}) \%=(-100) \frac{(+F e)-(-F e)}{(+F e)}$

WF9 genotype showed the highest value for (POD) activity under both treatments of iron. In plants grown with adequate Fe supply in the growth media, the POD activity in leaves of WF9 genotype was $(15.5 \mathrm{U} / \mathrm{g} \mathrm{F}$.W/min) and under iron deficient treatment was $(14.20 \mathrm{U} / \mathrm{g} \mathrm{F} . \mathrm{W} / \mathrm{min})$ and the relative reduction was $(8.40 \%)$. In contrast, POD activity in leaves of ys1 plants grown in adequate $\mathrm{Fe}$ supply was (9.2 U/g F.W/min), while under Fe deficient treatment the POD activity was $(4.3 \mathrm{U} / \mathrm{g} \mathrm{F} . \mathrm{W} / \mathrm{min})$. 
Table 7. Maize genotypes $(\mathrm{G})$ arranged in ascending order according to percentage Reduction (RD\%) due to Fe deficiency for the different plant parameters used to evaluate Fe efficient and inefficient genotypes

\begin{tabular}{|c|c|c|c|c|c|c|c|c|c|c|c|}
\hline \multicolumn{2}{|c|}{$\begin{array}{l}\text { Shoot dry } \\
\text { weight (g/plant) }\end{array}$} & \multicolumn{2}{|c|}{$\begin{array}{l}\text { Fe-concentration } \\
(\mu \mathrm{g} / \mathrm{g} D W)\end{array}$} & \multicolumn{2}{|c|}{$\begin{array}{l}\text { Iron uptake } \\
(\mu \mathrm{g} / \text { plant })\end{array}$} & \multicolumn{2}{|c|}{$\begin{array}{l}\text { Active iron } \\
\left(\mathrm{Fe}^{2+}\right) \mu \mathrm{g} / \mathrm{g} \mathrm{F} . \mathrm{W}\end{array}$} & \multicolumn{2}{|c|}{$\begin{array}{l}\text { POD activity } \\
(\mathrm{U} / \mathrm{g} . \mathrm{F} . \mathrm{W} / \mathrm{min})\end{array}$} & \multicolumn{2}{|c|}{$\begin{array}{l}\text { Total Chlorophyll } \\
(\mathrm{mg} / \mathrm{g} \mathrm{F} . \mathrm{W})\end{array}$} \\
\hline $\mathrm{G}$ & RD\% & $\mathrm{G}$ & RD\% & $\mathrm{G}$ & RD\% & $\mathrm{G}$ & RD\% & $\mathrm{G}$ & RD\% & $\mathrm{G}$ & RD $\%$ \\
\hline WF9 & -9 & 104 & -4 & WF9 & -16 & 104 & -22.9 & WF9 & -8.4 & WF9 & -42.9 \\
\hline 628 & -13 & 34 & -4.4 & 34 & -18 & WF9 & -24.0 & 34 & -19.5 & 34 & -44.6 \\
\hline 639 & -13 & 7 & -4.5 & 602 & -23 & 628 & -26.3 & 104 & -24.8 & 602 & -44.8 \\
\hline 34 & -14 & 602 & -5.5 & 628 & -24 & 34 & -27.1 & 653 & -26.3 & 7 & -49.2 \\
\hline 602 & -18 & WF9 & -6.8 & 7 & -32 & 602 & -27.9 & 628 & -28.6 & 628 & -51.1 \\
\hline 7 & -29 & 653 & -11.3 & 104 & -36 & 653 & -28.9 & 602 & -33.3 & 653 & -54.8 \\
\hline 104 & -33 & 628 & -13 & 653 & -41 & 7 & -29.6 & 7 & -37.4 & 104 & -55.2 \\
\hline 653 & -33 & 62 & -42 & 639 & -62 & 62 & -37.6 & 639 & -42.1 & 639 & -64.5 \\
\hline 62 & -43 & $\mathrm{ys}_{1}$ & -47 & 62 & -66 & 639 & -38.6 & 62 & -50 & 62 & -65.4 \\
\hline ys 1 & -43 & 639 & -56.6 & ys 1 & -70 & ys 1 & -47.4 & ys 1 & -53.3 & $\mathrm{ys}_{1}$ & -72.1 \\
\hline
\end{tabular}

The relative reduction in POD activity was (53.3\%). The magnitude inhibition in POD activity due to $\mathrm{Fe}$ deficiency was clearly observed in 639, 62 and ys1 genotypes, the values were $3.3,5.3$ and $4.3(\mathrm{U} / \mathrm{g}$ $\mathrm{F} . \mathrm{W} / \mathrm{min}$ ) (more than 42,50 and $53 \%$ depression). It is also interesting to note that POD activity in the fresh leaves of WF9 maize genotype, grown in either adequate or deficient Fe treatment, showed more or less the same value (15.5 and $14.2 \mathrm{U} / \mathrm{g} \mathrm{F} . \mathrm{W} / \mathrm{min})$. Genotype WF9 is known to be more efficient in the uptake and translocation of Fe from the roots into the leaves tissues.

Iron deficiency has been generally known to affect plant growth in several plant species (Rombolà et al., 2005; Pestana et al., 2005). As shown above in our results, significant differences in the pattern of plant growth were found to depend on the treatment and genotype. Furthermore, it was noticed that Fe deficiency caused reduced activity of POD enzyme. The reduction in POD activity was higher in the susceptible genotype (ys1) when compared with the non susceptible one (WF9). These results suggested that under Fe deficiency, the tolerant genotype tried to keep Fe-dependent PODs functioning, probably to counteract $\mathrm{H}_{2} \mathrm{O}_{2}$ accumulation. In general, it can be suggested that $\mathrm{Fe}$ deficiency led to a drastic decrease in POD activity in the susceptible genotype (ys1) when compared with the tolerant one (WF9), indicating that the $\mathrm{H}_{2} \mathrm{O}_{2}$ scavenging mechanism was less effective in the susceptible genotype (ys1). It turned out that the active involvement of this antioxidant enzyme was related, at least in part, to the tolerance to Fe-deficiency-induced oxidative stress.

Susceptibilities of the various maize genotypes were expressed as percentage reduction, from $\mathrm{Fe}$ sufficient level, due to $\mathrm{Fe}$ deficiency. These calculations were made for the different plant parameters used for screening the maize genotypes in the present study and arranged in ascending order according to the percentage reduction ( $\mathrm{RD} \%$ ) values (Table 7$)$. WF9, as the $\mathrm{Fe}$ efficient indicator and genotype (34) were the less affected genotypes and occupied the top of the table in four parameters out of six. On the other hand, the $\mathrm{Fe}$ inefficient indicator genotype (ys1) was the most affected genotype and occupied the bottom of the table in five parameters out of six. Similar response to Fe deficiency was noticed for genotype (62), it occupied the bottom of the table in four parameters out of six.

\section{Conclusion}

Although visual diagnostic symptoms are an extremely valuable tool for the rapid evaluation of the nutrient status of a plant, they are only some of the tools available. Other major tools include plants fresh and dry weights, tissue analysis, chlorophyll content, enzymes activity and others. These methods all vary in their precision, rapidity and their ability to predict future nutrient status. Because of the close interaction between plant growth and the environment, all predictions of future nutrient status must make assumptions about how the environment will change in that time frame. The other tools adopted in this study to evaluate the eight maize genotypes in addition to the Fe efficient (WF9) and the Fe inefficient (ys1) genotypes were shoot dry weight, Fe concentration, Fe uptake, active iron content, chlorophyll content and peroxidase activity. In general, the results indicated that the present maize genotypes showed different response when grown in Fe deficient media and could be classified according to the above mentioned parameters to efficient, moderate and inefficient. However, some genotypes showed different behavior concerning Fe efficiency when compared by different tools. For instance, genotype (639) was classified by shoot dry weight parameter as Fe efficient while it was classified as Fe inefficient by adopting Fe concentration as a parameter for evaluating the present maize genotypes for Fe efficiency.

\section{Acknowledgement}

This work was conducted as part of the EgyptianGerman project Micronutrients and Plant Nutrition Problems in Egypt, Implemented by the National Research Centre, Cairo (Coordinator: Prof. M.M. ElFouly) and the Institute of Plant Nutrition (Prof. U. Schmidhalter). This project was supported by the 
Egyptian Academy of Scientific Research and Technology (ASRT) and the German Federal Ministry for Economic Cooperation and Development (BMZE) through the German Agency for Technical Cooperation (GIZ).

\section{Author's Contributions}

All authors equally contributed in this work.

\section{Ethics}

This article is original and contains unpublished material. The corresponding author confirms that all of the other authors have read and approved the manuscript and no ethical issues involved.

\section{References}

Abadia, J., 1992. Leaf responses to Fe deficiency: A review. J. Plant Nutr., 15: 1699-1713. DOI: $10.1080 / 01904169209364432$

Abadia, J., M. Tagliavini, R. Grasa, A. Belkhodja and A. Abadia et al., 2000. Using the flower Fe concentration for estimating chlorosis status in fruit tree orchards: A summary report. J. Plant Nutr., 23: 2023-33. DOI: 10.1080/01904160009382162

Amako, K., G.X. Chen and K. Asada, 1994. Separate assays specific for ascorbate peroxidase and guaiacol peroxidase and for the chloroplastic and cytosolic isozymes of ascorbate peroxidase in plants. Plant Cell Physiol., 35: 497-504.

Cakmak, I., M. Kalayci, H. Ekiz, H.J. Braun and A. Yilmaz, 1999. Zinc deficiency as a practical problem in plant and human nutrition in Turkey: A NATO-science for stability project. Field Crops Res., 60: 175-188. DOI: 10.1016/S0378-4290(98)00139-7

Celik, H. and V. Katkat, 2008. Effects of bicarbonate and iron-deprivation on growth of different maize varieties. Am. Eurasian J. Agric. Environ. Sci., 3: 169-178.

Chapman, H.D. and P.E. Pratt, 1978. Methods of analysis for soils, plants and waters. University of California.

Clark, R.B. and J.C. Brown, 1974. Internal root control of iron uptake and utilization in maize genotypes. Plant Soil, 40: 669-677. DOI: 10.1007/BF00010522

El-Baz, F.K., E.A. EL-Mobde, Z. Salama and A.A. Mohamed, 1998. Determination of $\mathrm{Fe}^{2+}$ and soluble zinc as biochemical indicators for the diagnosis of iron and zinc deficiency in snap bean (Phaseolus vulgaris) and faba bean (Vicia faba) plants. Egyptian J. Physiol. Sci., 2: 25-39.

El-Bendary, A. A., A. Abdel-Aziz, Y. Mabrouk and A. Y. El-Metainy, 1999. Utilization of RAPD molecular markers for screening maize genotypes for irondeficiency genes. Arab J. Biotech., 2: 161-166.
El-Bendary, A.A. and V. Roemheld, 1998. Evaluation of Fe-efficiency in corn lines. Alex. J. Agric. Res., 43: 39-50.

El-Bendary, A.A. and Z.A. Salama, 1998. Differential response of faba bean varieties to Fe-deficiency. J. Agric. Sci. Mansoura Univ., 23: 5459-5466.

Godsey, C.B., J.P. Schmidt, A.J. Schlegel, R.K. Taylor and C.R. Thompson et al., 2003. Correcting iron deficiency in corn with seed row-applied iron sulfate. Agron. J., 95: 160-166.

DOI: 10.2134/agronj2003.1600

Gogorcena, Y., N. Molias, A. Larbi, J. Abadía and A. Abadía. 2001. Characterization of the responses of cork oak (Quercus suber) to iron deficiency. Tree Physiol., 2: 1335-1340.

DOI: $10.1093 /$ treephys/21.18.1335

Hoagland, D.R. and D.I. Arnon, 1950. The water-culture method for growing plants without soil. California Agric. Experiment Station Circular, 347: 1-32.

Jelali, N., S. Moez, W. Dhifi, W. Mnif, C. Abdelly and M. Gharsalli, 2012. Secondary metabolism responses in two Pisum sativum L. cultivated under Fe deficiency conditions. Afr. J. Biotechnol., 11: 14828-14836.

Katyal, J.C. and B.D. Sharma, 1980. A new technique of plant analysis to resolve iron chlorosis. Plant Soil, 55: 105-119. DOI: 10.1007/BF02149714

Khoshgoftarmanesh, A.H., R. Schulin, R.L. Chaney, B.Daneshbakhsh and M. Afyuni, 2010. Micronutrient-efficient genotypes for crop yield and nutritional quality in sustainable agriculture. A review. Agron. Sustain. Dev., 30: 83-107.

DOI: $10.1051 /$ agro/2009017

Krishnasamy, R., D. Jegadeeswari, U. Surendran and C. Sudhalakshmi, 2005. Screening of sorghum (Sorghum bicolor) genotypes for their iron efficiency. World J. Agric. Sci., 1: 98-100.

Lichtenthaler, H.K., 1987. Chlorophylls and carotenoids: Pigments of photosynthetic biomembranes. Methods Enzymol., 148: 350-382. DOI: 10.1016/0076-6879(87)48036-1

Little, T.M. and F.J. Hills, 1978. Agricultural Experimentation: Design and Analysis. 1st Edn., John Wiley and Sons, Inc., N.Y. USA, ISBN-10: 0471023523, pp: 350.

Mansfield, M.A. and J.L. Key, 1987. Synthesis of low molecular weight heat shock proteins in plants. Plant Physiol., 84: 1007-1017.

Mehrotra, S.C. and P. Gupta, 1990. Screening of chickpea (Cicer arietinum) varieties under iron deficiency-stress conditions using biochemical indicators. Indian J. Agric. Sci., 60: 566-568. 
Mengel, K., 1994. Iron availability in plant tissues-iron chlorosis on calcareous soils. Plant Soil, 165: 275-283. DOI: $10.1007 / \mathrm{BF} 00008070$

Misra, A. and N.K. Srivastava, 1994. Influence of iron nutrition on chlorophyll contents, photosynthesis and essential monoterpene oil(s) in Java citronella (Cymbopogon winterianus Jowitt). Photosynthetica, 30: 425-434.

Mohamed, A.A., F.K. El-Baz and R.K.H.M. Khalifa, 2003. Genotypic differences of tow wheat cultivars for the enzymes activity, amino acids and protein profile under Fe deficiency. J. Biol. Sci., 3: 864-874.

Nenova, V. and I. Stoyanov, 1999. Physiological and biochemical changes in young maize plants under iron deficiency. 3. Concentration and distribution of some nutrient elements. J. Plant Nutr., 22: 565-578. DOI: $10.1080 / 01904169909365652$

Ohwaki, Y. and K. Sugahara, 1993. Genotypical differences in responses to iron deficiency between sensitive and resistant cultivars of chickpea (Cicer arietinum). Plant Soil, 155: 473-476. DOI: 10.1007/BF00025086

Pestana, M., A. de Varennes, J. Abadı'a and E.A. Faria, 2005. Differential tolerance to iron deficiency of citrus rootstocks grown in nutrient solution. Sci. Hortic., 104: 25-36. DOI: $10.1016 /$ j.scienta.2004.07.007

Pestana, M., A. de Varennes and E.A. Faria, 2003. Diagnosis and correction of iron chlorosis in fruit trees: A review. Food. Agri. Environ., 1: 46-51.

Price, C.A., 1968. Iron Compounds and plant nutrition. Ann. Rev. Plant Physiol., 19: 239-248. DOI: 10.1146/annurev.pp.19.060168.001323

Ramirez, L.M., N. Claassen, A. Ubiera, H. Werner and A.M. Moawad, 2002. Effect of phosphorus, potassium and zinc fertilizers on iron toxicity in wetland rice (Oryza sativa L.). Plant Soil, 239: 197-206.

DOI: 10.1023/A:1015099422778
Rombolà, A.D., Y. Gogorcena, A. Larbi, F. Morales and E. Baldi et al., 2005. Iron deficiency-induced changes in carbon fixation and leaf elemental composition of sugar beet (Beta vulgaris) plants. Plant Soil, 271: 39-45. DOI: $10.1007 / \mathrm{s} 11104-004-2001-\mathrm{x}$

Russell, D.F., 1986. MSTAT-C package programme. Crop and Soil Science Department, Michigan State University, USA.

Salama, Z.A., H.S. EL-Beltagi and D.M. El-Hariri, 2009. Effect of $\mathrm{Fe}$ deficiency on antioxidant system in leaves of three flax cultivars. Not. Bot. Hort. Agrobot. Cluj., 37: 122-128.

Singh, A.L. and M.P. Sahu, 1993. Effects of phosphate carriers, iron and indoleacetic acid on iron nutrition and productivity of peanut on a calcareous soil. J. Plant Nutr., 16: 1847-1855. DOI: $10.1080 / 01904169309364655$

Takkar, P.N. and N.P. Kaur, 1984. $\mathrm{HCl}$ method for $\mathrm{Fe}^{2+}$ estimation to resolve iron chlorosis in plants. J. Plant Nutr., 7: 81-90. DOI: 10.1080/01904168409363176

Terry, N. and J. Abadía, 1986. Function of iron in chloroplast. J. Plant Nutr., 9: 609-646. DOI: $10.1080 / 01904168609363470$

Terry, N., 1980. Limiting factors in photosynthesis. I. Use of iron stress to control photochemical capacity in vivo. Plant Physiol., 65: 114-120. DOI: $10.1104 /$ pp.65.1.114

Wallace, A., E.M. Romney and G.W. Alexander, 1976a. Lime-induced chlorosis caused by excess irrigation water. Cornmuni. Soil Sci. Plant Anal., 7: 47-49. DOI: 10.1080/00103627609366611

Zhang, X.W., Y.J. Dong, X.K. Qiu, G.Q. Hu and Y.H. Wang et al., 2012. Exogenous nitric oxide alleviates iron-deficiency chlorosis in peanut growing on calcareous soil. Plant Soil Environ., 58: 111-120. 